\title{
PREFACE TO THE REVISED EDITION
}

Publication of a revised edition of this work was made desirable by the decision of Doubleday and Anchor to let the first one go out of print in 1975, despite a generally favorable response. One of their reasons for doing so was the excessive length of the first edition, which came to 750 pages. Partly as a consequence of this, in this revised edition we have cut approximately one-third of the material presented in the earlier version, including the entire first and fourth parts. Part One of the earlier version consisted of two introductory chapters, the first analyzing explanations put forward by old socialists for the exceptional weakness of American socialism, and the second presenting a dialogue between the two editors on the subject. Although both contained valuable material, they are now somewhat out of date. The same thing was true of Part Four of the first edition, which consisted of two essays on the then current status and prospects of the New Left, a movement that has since largely collapsed. The new version, therefore, contains only two, renumbered sections. Part One deals with the internal difficulties that the American socialist movement encountered in its efforts to become a mass party, unlike the socialist movements in western Europe. Part Two examines the external or societal reasons for its lack of success.

In response to reviewers' comments on the first edition and in order to bring Part One up to date, three new chapters have been added to that section. The first one, a new Chapter 6, deals with the inhibiting effect on efforts to develop a mass socialist movement in America of racial divisions within the working class. Chapter 7, on ethnicity and class, attempts the same thing in relation to immigrant workers coming to the United States from abroad. Chapter 8, on socialism and women, deals with a similar issue from a somewhat different point of view. Beyond this, the various 


\section{$x$ / PREFACE TO THE REVISED EDITION}

disclaimers that were put into the first edition concerning the limited nature of this work and on other matters still stand.

It is hoped that the briefer nature of this volume and the new material that has been added to it will make it attractive as a collection of readings in history, sociology, and political science for both the general reader and for use in college courses. The debate format-with scholars currently working in the field writing essays of comment on the previously published material and the previous authors writing a brief reply-has been retained to liven up the issues under discussion.

For readers who would like to pursue the subject further, a chronology or list of important dates has been added at the beginning of the book, and a selected bibliography at the back. Even though the bulk of the essays concern the American socialist movement, which reached its peak before the First World War, because of numerous references to the Communist Party in the text, both of these lists cover later radical movements as well. Readers interested in the views of the two editors on the relative weakness of American socialism are referred to our various works cited in the bibliography and to our essay in the first edition of this book, Laslett and Lipset, "Social Scientists View the Problem," pp. 25-82.

November 1983

John H. M. Laslett, U.C.L.A.

Seymour Martin Lipset, Stanford University 